\title{
Rethinking evidence-based practice for children's mental health
}

"Efficiency is concerned with doing things right. Effectiveness is doing the right things." Drucker, 1993

$\mathrm{T}$ ypically, evidence-based practice (EBP) refers to health practitioners applying the best currently available research evidence in the provision of health services. In other words, EBP challenges practitioners to "do things right" and to "do the right things". EBP originated in medicine, where an estimated 10000 new randomised controlled trials (RCTs) are published every year but where an estimated $20 \%-40 \%$ of services still do not reflect the best research evidence. ${ }^{1}$ Related disciplines such as psychology have also embraced the EBP movement to bridge research and practice in order to improve outcomes for people with mental disorders. ${ }^{2}$ In children's mental health, high levels of unmet service need suggest a strong role for EBP. At any given time $14 \%$ of children experience mental disorders that cause significant distress and impair their functioning, yet only $25 \%$ of these children receive specialised mental health treatment services. ${ }^{3}$ It is also clear that children's mental health services often fail to reflect the best available research evidence, leading researchers to argue that EBP is an ethical imperative if we are to improve children's mental health. ${ }^{4}$

Despite being widely advocated, EBP has nevertheless proved difficult to implement. To some extent implementation barriers are a result of a restricted focus on interventions designed to change simple behaviours performed by individual practitioners, such as prescribing by physicians. These interventions have had only modest effects and need to be integrated with larger organisational and system changes that support EBP. ${ }^{1}$ However, a greater challenge may be posed by controversies about EBP's narrow definitions of "evidence," particularly when applied in mental health. ${ }^{6}$ Here, we discuss the controversies with regard to implementing EBP in children's mental health. We illustrate the issues based on our experience as researchers engaged in an ongoing partnership with children's mental health practitioners and with the policy makers who manage services in British Columbia, Canada. We conclude with suggestions for rethinking EBP in order to improve children's mental health.

\section{CONTROVERSIES ABOUT EBP}

Although EBP is widely promoted by researchers and others, controversies have emerged about defining "evidence" too narrowly, particularly in diverse fields like mental health. With its origins in the modernist scientific paradigm and its focus on rationalism and objectivity, EBP has privileged some kinds of knowledge over others. ${ }^{6}$ The hierarchies of evidence used in EBP relegate individual experience to the lowest rung and neglect qualitative research in favour of quantitative. ${ }^{7}$ The modernist paradigm is conveyed by language such as "knowledge transfer" which implies unidirectional transmission from researchers to practitioners, rather than reciprocity in the creation of knowledge.

Three particular controversies have emerged about EBP in mental health. First, EBP privileges RCTs that address efficacy in controlled research settings, but practitioners require research evidence on effectiveness in typical practice settings. What works in research settings may not be the same as what works in practice. Research that addresses the complexities of typical practice settings is lacking. ${ }^{2}$ Further, the reliance on RCTs leaves many relevant questions unanswered. For instance, therapeutic relationships are central to mental health practice but efficacy research typically focuses on techniques such as cognitive behavioural therapy (CBT) that can be investigated quantitatively. ${ }^{6}$ Finally, efficacy research has been used to limit the types and duration of services that are funded by managed healthcare organisations in the United States, fuelling concerns that EBP will be used too narrowly by policy makers in the service of efficiency. ${ }^{6}$

There are additional controversies about implementing EBP in children's mental health. An understanding of healthy child development is central to children's mental health. Development involves continuous and dynamic interactions between children and their environments over time, and is inextricably linked to the ecological context that children develop within; families, schools, and communities. ${ }^{2}$ The dynamic nature of development means that what is efficacious for children at one stage may not be at another. For example, it is not known whether efficacious treatments such as CBT for anxiety apply across all age groups or apply to children with concurrent disorders, meaning that practitioners must constantly extrapolate from the existing research evidence. Also, practitioners must always consider a child's family, school, and community in the provision of services, but most RCTs do not address these dimensions. ${ }^{2}$ Compounding the situation, children's mental health services typically entail a diverse array of both practitioners (such as psychologists, social workers, nurses, and psychiatrists) and sectors (such as health, social services, education, child protection, and justice). Fragmentation is endemic across these disciplines and sectors, making it difficult to even achieve agreement on the role of EBP. ${ }^{8}$ These controversies have prompted calls for new approaches to implementing EBP in children's mental health that are rigorous but that also take developmental and practice contexts into account. ${ }^{2}$

\section{IMPLEMENTING EBP IN BRITISH COLUMBIA}

As researchers, we have been engaged in an ongoing partnership with practitioners and policy makers in British Columbia with the goal of improving children's mental health. Our partnership illustrates many of the controversies involved in implementing EBP. Policy makers initially asked us to summarise the relevant research evidence on efficacious interventions for both prevention and treatment for a range of children's mental disorders. Policy makers then used this research summary to inform a new Child and Youth Mental Health Plan for British Columbia. ${ }^{9}$ This plan incorporates

Abbreviations: $C B T$, cognitive behavioural therapy; $E B P$, evidencebased practice; $R C T$, randomised controlled trial. 
prevention, treatment, and outcome monitoring, with an explicit focus on EBP. We now provide ongoing research support and education as the plan is implemented.

In our experience, many practitioners have been sceptical about EBP. The lack of effectiveness research has been a stumbling block, as has the lack of research incorporating developmental and practice contexts. Thus, practitioners questioned whether the research evidence was applicable to the situations they encountered on a daily basis. Also, when new techniques such as CBT were suggested based on the efficacy research, many practitioners responded that they were not trained in those techniques and that having policy makers sanction particular approaches could come to limit the service choices available in British Columbia's public health system. There were also challenges related to the interdisciplinary nature of children's mental health. We found that some disciplines embraced EBP's quantitative perspective but others focused on its limitations, creating differences of opinion among practitioners. Further, intersectoral fragmentation meant that research minded policy makers leading the plan's implementation had to market EBP to multiple diverse groups.

As researchers engaged in a partnership with practitioners and policy makers, we have worked with both groups to respond to the scepticism about EBP. For example, to address concerns about effectiveness, we have encouraged practitioners and policy makers to rigorously evaluate child outcomes at the local, regional, and provincial levels. By evaluating outcomes, we postulate that effectiveness information can be generated on new and existing services. To address the lack of training, active educational strategies have been used to provide education on CBT and other efficacious techniques. This training has made many practitioners more receptive to adding new techniques to their repertoire. We have also worked closely with policy makers to promote EBP with multiple diverse groups and to create an organisational environment that encourages EBP. However, most importantly for us as researchers, our partnership has educated us about the concerns of practitioners and policy makers which echo those expressed in the literature. ${ }^{10} \mathrm{EBP}$ is too narrowly defined if it simply means the application of RCT evidence to practice. Therefore, we concur that new forms of research are urgently needed and we suggest that EBP must be redefined in a rigorous yet more inclusive way for children's mental health.

\section{RETHINKING EBP FOR CHILDREN'S MENTAL HEALTH}

Controversies about EBP can be unhelpful when they polarise debates, pitting practitioners against researchers. Researchers and practitioners are not at odds but rather share a common goal-to improve children's mental health. This makes research and practice interdependent, a case of "both/and" rather than "either/or". Moreover, researchers and practitioners share a common epistemology. Thoughtful work in children's mental health research and practice always comprises a synthesis of multiple forms of evidence: individual experience (of the one researcher or practitioner, or the one child or family), aggregate experience (of the many children and families), qualitative evidence (about values, meaning, and preferences) and quantitative evidence (about issues such as causation, prevention, and treatment). Each of these kinds of knowledge is required to make good decisions.

As a step towards recognising their interdependence with practitioners, researchers could acknowledge the limitations of EBP's current hierarchy of evidence and could be more inclusive of complementary forms of knowledge. The existing research evidence in children's mental health does not address the developmental and practice contexts or the interdisciplinary and intersectoral challenges that are faced when implementing EBP. These issues need to be included in new research on children's mental health and on implementing EBP. ${ }^{2}$ Rigorous qualitative methodologies could be promoted to conduct research that incorporates practitioners' experiences and that investigates interventions in developmental and practice contexts (see Gabbay \& May, 2004). ${ }^{11}$ Quantitative research could also be better positioned as one kind of evidence, but not the only kind. ${ }^{7}$ Given the unmet children's service needs, it is also imperative that practitioners be open to EBP. In this respect, practitioners could be more rigorous in systematically seeking and applying multiple kinds of evidence, including quantitative. Best available RCT evidence should be used as a guide where it is available.

\section{CONCLUSIONS}

For researchers and practitioners in children's mental health, both the lack of appropriate research and the controversies about EBP are ultimately instructive. As well as sharing the common goal of improving children's mental health, researchers and practitioners also share accountability to children, families, and communities for how well they are meeting this goal. There is always ambiguity when dealing with multiple perspectives and multiple kinds of evidence. ${ }^{8}$ However, vigilance can be maintained amid ambiguity by asking, as Drucker suggests, how do we know that we are "doing things right" and that we are "doing the right things"? ${ }^{12}$ Thoughtful researchers and practitioners ask these questions continuously. Applying RCT evidence in practice is one essential component of "doing things right" and "doing the right things", but it is not the only component. We suggest rethinking EBP to better acknowledge the lack of research on developmental and practice contexts and to better reflect the multiple sources of evidence that are needed in children's mental health. There are high levels of unmet service need in children's mental health. This problem makes it imperative for researchers and practitioners to conduct new research and resolve the controversies together in order to meet their common goal.

\section{ACKNOWLEDGEMENTS}

We thank George McLauchlin and Cody Shepherd for their contributions to the ideas shared in this paper. We are also grateful to Child and Youth Mental Health Services with the British Columbia Ministry of Children and Family Development who funded this work. Our ongoing partnership with them has educated us about evidence-based practice in children's mental health. Charlotte Waddell also holds a Scholar Award from the Michael Smith Foundation for Health Research.

C WADDELL, R GODDERIS Mental Health Evaluation and Community Consultation Unit, Department of Psychiatry, Faculty of Medicine, The University of British Columbia Vancouver, British Columbia, Canada

\section{REFERENCES}

1 Grol R, Grimshaw J. From best evidence to best practice: Effective implementation of change in patients' care. Lancet 2003;362:1225-30.

2 Hoagwood K, Burns BJ, Kiser L, et al. Evidence-based practice in child and adolescent mental health services. Psychiatr Serv 2001;52:1179-89.

3 Waddell C, McEwan K, Shepherd CA, et al. A public health strategy to improve the mental health of Canadian children. Can J Psychiatry 2005:50:226-33.

4 Hoagwood K. The policy context for child and adolescent mental health services: Implications for systems reform and basic science development. Ann N Y Acad Sci 2003;1008:140-8. 
62

5 Szatmari P. The art of evidence-based child psychiatry. Evid Based Ment Health 2003;6:99-100.

6 Tanenbaum SJ. Evidence-based practice as mental health policy: three controversies and a caveat. Health Aff 2005:24: 163-74.

7 Davies H, Nutley SM, Smith PC, eds. What works? Evidence-based policy and practice in public services. Bristol, UK: The Policy Press, 2000.

8 Waddell C, Lavis JN, Abelson J, et al. Research use in children's mental health policy in Canada: Maintaining vigilance amid ambiguity. Soc Sci Med 2005 (in press).
9 British Columbia Ministry of Children and Family Development. Child and Youth Mental Health Plan for British Columbia. Victoria, British Columbia: Ministry of Children and Family Development, 2003.

10 upta M. Evidence-based medicine: ethically obligatory or ethically suspect? Evid Based Ment Health 2004;7:96-7.

11 Gabbay J, May A. Evidence based guidelines or collectively constructed "mindlines?": Ethnographic study of knowledge management in primary care. BMJ 2004;329:1013-18.

12 Drucker P. Management: tasks, responsibilities, practices. New York, NY: HarperBusiness, 1993 (first published in 1973)

\section{bmjupdates $^{+}$, a new FREE service for evidence-based clinical practice $^{\dagger}$}

T he BMJ Publishing Group and the Health Information Research Unit at McMaster University are pleased to announce a new, advanced information service to support clinical practitioners to keep up to date and to find current best evidence for practice. The service, bmjupdates+ (http://bmjupdates.com), has this goal: to provide clinical practitioners with the best new evidence concerning important advances in health care, exactly tailored to their interests.

For a typical clinician, aiming to keep up with the most important "need to know" studies and reviews, bmjupdates ${ }^{+}$ uses a 2 step process (see figure below) to shrink about 50000 articles per year in $>100$ clinical journals to the most important 1-2 articles per month, a "noise reduction" of over $99.9 \%$.

bmjupdates $^{+}$uses the same, explicit, and reproducible quality filters as Evidence-Based Medicine (http://hiru.mcmaster. ca/ebmj/Ebmp p.htm). Applying these criteria to each article in over 110 premier clinical journals (about 50000 articles per year), about 3000 articles (6\%) pass muster-that is, have adequate methods to support their conclusions for key aspects of clinical care.

All (and only!) articles that pass the scientific criteria are assessed for relevance and newsworthiness on 7 point scales via the McMaster Online Rating of Evidence (MORE) system (http://hiru.mcmaster.ca/more/AboutMORE.htm). These ratings are specific for each pertinent clinical discipline for a given article and are provided by at least 3 practicing physicians for each discipline, selected from a panel of over 2000 worldwide. (If you are a physician in independent clinical practice, you are invited to join MORE. Email MORE@McMaster.ca.)

The resulting quality/relevance/newsworthiness-rated literature service has many features to help practitioners keep on top of the current best evidence for clinical practice.

Alerts: having the best new evidence find you. If you register with bmjupdates ${ }^{+}$, and indicate a clinical discipline (eg, general practice), then you will receive alerts whenever an article is judged by the raters in your discipline to meet the cut-off scores for relevance and newsworthiness that you set. Depending on your discipline, if you elect to receive alerts for articles that are judged by your peers to be at least $6 / 7$ for relevance ("definitely relevant") and 6/7 for newsworthiness ("useful information that most practitioners probably don't know"), then you can expect to receive about $1-2$ alerts per month for articles that are highly important for your clinical practice: a highly efficient way to keep up to date.

Search: finding the best evidence when you need it. bmjupdates $^{+}$also has a searchable database of alerts back to 2002. You can search this database at any time. If you have

${ }^{\dagger}$ This editorial was first published in Evidence-Based Medicine 2005; 10:35.
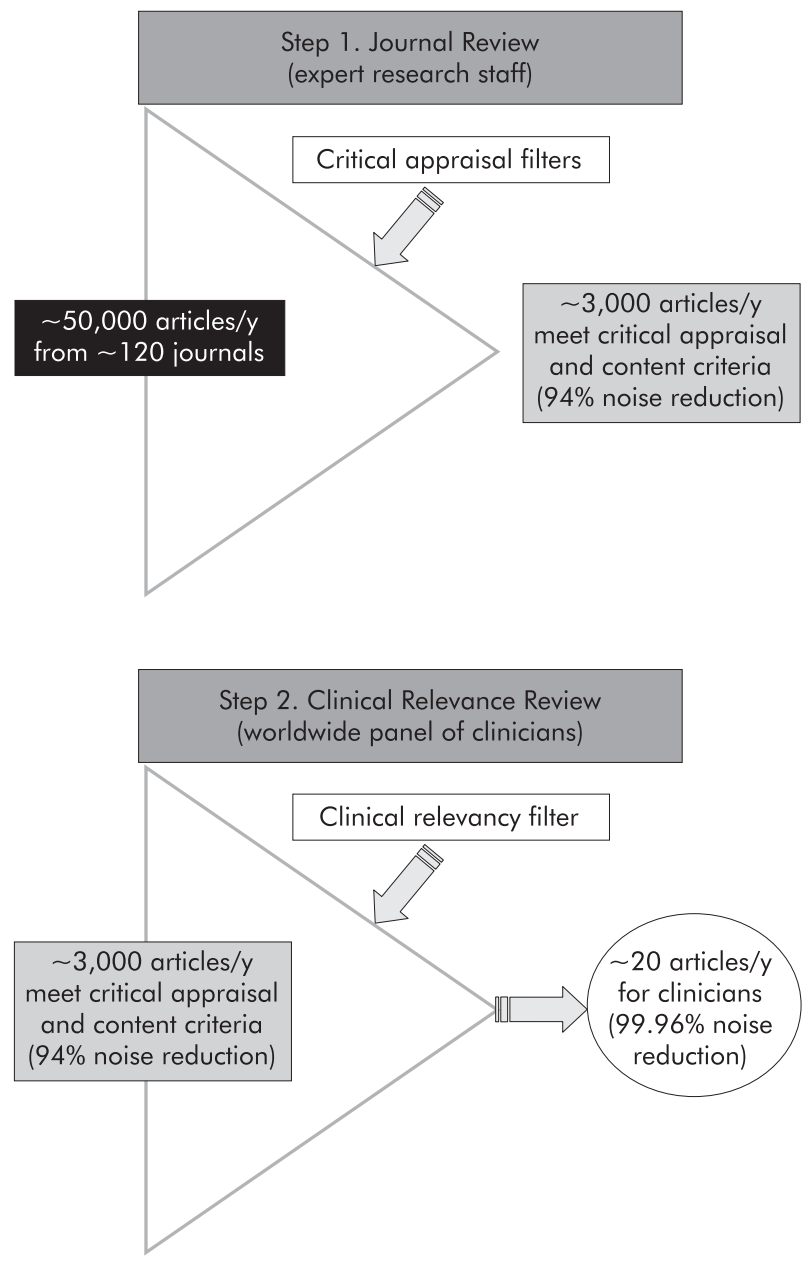

indicated a clinical discipline, the default is set so that the search will be done for only those articles judged by raters in your discipline to be relevant.

BMJ Summaries. The articles most highly rated by clinicians are summarised by BMJ writers.

Global Links provide connections to a Featured Article, the highest rated article for the preceding weeks, and to Headlines, a popular feature (compliments of the UK National Health Service) that examines the available evidence behind news headlines about health problems.

BMJ Resources. The BMJ Publishing Group is a leader in providing evidence-based resources for clinical practice. Many of these are listed in the BMJ Resources box in the 
lower left column of each screen. You can link directly to these resources by clicking on their titles.

Evidence-Based Tools and Services. Links are provided

to a selection of evidence-based utilities, services, and guides.

bmjupdates + has been designed to help practitioners

succeed in keeping up with important medical advances. Try it out at http://bmjupdates.com. (And did I mention that it is free...!).

R BRIAN HAYNES, MD, PHD McMaster University, Hamilton, Ontario, Canada

\section{Clinical Evidence - Call for contributors}

Clinical Evidence is a regularly updated evidence-based journal available worldwide both as a paper version and on the internet. Clinical Evidence needs to recruit a number of new contributors. Contributors are healthcare professionals or epidemiologists with experience in evidence-based medicine and the ability to write in a concise and structured way.

Areas for which we are currently seeking authors:

- Child health: nocturnal enuresis

- Eye disorders: bacterial conjunctivitis

- Male health: prostate cancer (metastatic)

- Women's health: pre-menstrual syndrome; pyelonephritis in non-pregnant women

However, we are always looking for others, so do not let this list discourage you.

Being a contributor involves:

- Selecting from a validated, screened search (performed by in-house Information Specialists) epidemiologically sound studies for inclusion.

- Documenting your decisions about which studies to include on an inclusion and exclusion form, which we keep on file.

- Writing the text to a highly structured template (about 1500-3000 words), using evidence from the final studies chosen, within 8-10 weeks of receiving the literature search.

- Working with Clinical Evidence editors to ensure that the final text meets epidemiological and style standards.

- Updating the text every six months using any new, sound evidence that becomes available. The Clinical Evidence in-house team will conduct the searches for contributors; your task is simply to filter out high quality studies and incorporate them in the existing text.

- To expand the topic to include a new question about once every 12-18 months.

If you would like to become a contributor for Clinical Evidence or require more information about what this involves please send your contact details and a copy of your CV, clearly stating the clinical area you are interested in, to Klara Brunnhuber (kbrunnhuber@ bmigroup.com).

\section{Call for peer reviewers}

Clinical Evidence also needs to recruit a number of new peer reviewers specifically with an interest in the clinical areas stated above, and also others related to general practice. Peer reviewers are healthcare professionals or epidemiologists with experience in evidence-based medicine. As a peer reviewer you would be asked for your views on the clinical relevance, validity, and accessibility of specific topics within the journal, and their usefulness to the intended audience (international generalists and healthcare professionals, possibly with limited statistical knowledge). Topics are usually 1500-3000 words in length and we would ask you to review between 2-5 topics per year. The peer review process takes place throughout the year, and our turnaround time for each review is ideally 10-14 days.

If you are interested in becoming a peer reviewer for Clinical Evidence, please complete the peer review questionnaire at www.clinicalevidence.com or contact Klara Brunnhuber (kbrunnhuber@bmigroup.com). 